\title{
Erratum to: Clostridium Difficile Infection from a Surgical Perspective
}

\author{
Andreas M. Kaiser ${ }^{1} \cdot$ Rachel Hogen $^{1} \cdot$ Liliana Bordeianou $^{2} \cdot$ Karim Alavi $^{3}$. \\ Paul E. Wise ${ }^{4} \cdot$ Ranjan Sudan ${ }^{5}$ - On behalf of the CME Committee of the SSAT
}

Published online: 3 June 2015

(C) 2015 The Society for Surgery of the Alimentary Tract

\section{Erratum to J Gastrointest Surg \\ DOI 10.1007/s11605-015-2785-4}

The italicized Disclosure information listed for this article is incorrect. The correct information from the SSAT is below:

Disclosure Information: Authors: Andreas M. Kaiser, M.D. receives speaker fees from GI Health Foundation, and royalties from Uptodate and McGraw Hill Publisher. Rachel Hogen, M.D. has nothing to disclose. Liliana Bordeianou, M.D. has nothing to disclose. Karim Alavi,
M.D., MPH has nothing to disclose. Paul Wise, M.D. has nothing to disclose. Ranjan Sudan, M.D. has nothing to disclose. Editors-in-Chief: Jeffrey B. Matthews, M.D., has nothing to disclose; Charles Yeo, M.D., has nothing to disclose. CME Overseers: Arbiter: Jeffrey B. Matthews, M.D., has nothing to disclose; Vice-Arbiter: Guilherme M. Campos, M.D., Ph.D., has nothing to disclose; Question Reviewers: Michael Leitman, M.D. has reported no financial relationships with commercial interests; Matthias G. Stelzner, M.D., has reported no financial relationships with commercial interests.
The online version of the original article can be found at http://dx.doi.org/ $10.1007 / \mathrm{s} 11605-015-2785-4$.

Andreas M. Kaiser

akaiser@usc.edu

1 Department of Surgery, Division of Colorectal Surgery, Keck School of Medicine, University of Southern California, 1441 Eastlake Avenue, Suite 7418, Los Angeles 90033, CA, USA

2 Department of Surgery, Colorectal Surgery Program Massachusetts General Hospital, Boston, MA 02114, USA

3 Department of Surgery, UMass Memorial Medical Center, Worcester, MA, USA

4 Department of Surgery, Washington University School of Medicine, St. Louis, MO, USA

5 Department of Surgery, Duke University Medical Center, Durham, NC, USA 